\title{
Frequency and factors associated with carriage of multi-drug resistant commensal Escherichia coli among women attending antenatal clinics in Central India
}

Ashish Pathak ${ }^{1,2,3^{*}}$, Salesh P Chandrann ${ }^{4}$ Kalpana Mahadik ${ }^{5}$ Ragini Macaden ${ }^{4}$ and Cecilia Stålsby Lundborg ${ }^{1}$

\begin{abstract}
Background: Commensal Escherichia coli are a prominent reservoir of genes coding for antibiotic resistance and also responsible for endogenous infections in pregnant women. We studied the factors in pregnant women associated with carriage of multi-drug resistant (MDR) E. coli and genetic determinants of antibiotic resistance in them.

Methods: Women attending to Obstetric and Gynaecology department outpatient clinics for routine antenatal check-up were administered a questionnaire. Peri-anal swabs were collected for culture isolation and identification of E.coil. Antibiotic sensitivity was done using the Kirby-Bauer disc diffusion method as recommended by the CLSI guidelines. MICs for quinolones and third generation cephalosporins were done using the agar dilution method. Genes coding for production of beta lactamses and for the quinolone resistance determinant were screened by polymerase chain reaction. Rep-PCR was done on MDR isolates for detecting possible genetic similarity. Multiple logistic regression models were used to determine the independent factors associated with carriage of MDR isolates.

Results: A total of 710 isolates of E. coli from 710 women (mean age 26 years) were included in the study. Resistance to at least one antibiotic tested was detected in $94 \%$ of the $E$. coli isolates. A total of 109 isolates were ESBL producing and 35 isolates were MDR. In the MDR isolates $M I C_{50}$ and $M I C_{90}$ for quinolones and third generation cephalosporins were high for those isolates that carried bla $a_{\text {TEM }}$ gene (26 isolates) and bla isolates). Both bla TEM and bla $a_{\text {CTX-M }}$ genes were detected in 19 isolates. The commonest Plasmid Mediated Quinolone Resistance (PMQR) gene identified was aac $\left(6^{\prime}\right)-1 b-c r(n=23 / 25)$. All isolates carrying the PMQR genes were also positive for bla $a_{\mathrm{CTX}-\mathrm{M}}$ and bla $a_{\mathrm{TEM}}$ gene. Mutations in gyr $\mathrm{A}$ and par $\mathrm{C}$ genes were present in all $35 \mathrm{MDR}$ isolates. The statistically significant risk factors for carriage of MDR E. coli were graduate or post-graduate education, a self-employed status, a family size of more than 10 members, antibiotic usage in last four weeks, and history of hospitalization in the last four weeks.
\end{abstract}

Conclusions: The presence of genes coding for extended spectrum of beta lactamases and plasmid mediated quinolone resistance in commensal $E$. coli is disconcerting. The study provides strong basis good antibiotic stewardship.

\footnotetext{
* Correspondence: ashish.pathak@ki.se

${ }^{1}$ Global Health (IHCAR), Department of Public Health Sciences Karolinska

Institutet, Tomtebodavägen 18 A 9, Stockholm 17177, Sweden

${ }^{2}$ Department of Pediatrics, R.D. Gardi Medical College, Surasa, Ujjain 456010,

India

Full list of author information is available at the end of the article
} 


\section{Background}

The worldwide dissemination of plasmid-borne extendedspectrum beta-lactamases (ESBLs) in Enterobacteriaceae has become a major global public health problem [1]. Inappropriate use of antibiotic is the predominant selection pressure for antibiotic resistance and aids horizontal transfer of bacterial resistance [2]. The spread of multiresistant strains of bacteria in the community is compounded with a paucity of new classes of antibiotics effective against Gram-negative bacteria like Escherichia coli [3]. E. coli is the most common bacterial cause of urinary tract infections (UTI's) in women and also a major cause of catheter induced UTI, surgical site infections, intra-abdominal infections and sepsis in all age groups and meningitis in neonates [4]. The recent spread of New Delhi metallo-beta-lactamase-1 (NDM-1) producing bacteria emphasises the fact that resistant bacteria respect no geographical boundaries [5].

E. coli forms part of the bacteria commensal flora of the human gut. It has been identified as the predominant reservoir of antibiotic resistance genes [2]. Once acquired, these resistance genes are stable and are easily transferable to pathogenic bacteria [6]. The published studies on antibiotic resistance in commensal $E$. coli in resource-poor settings are limited as resistance monitoring is resource intensive, requires dedicated staff and a well-equipped laboratory [7-9].

During pregnancy many anatomical and physiological changes occur, which also affect the urinary tract. Asymptomatic bacteriuria is reported to occur in 2-10\% of pregnancies and E. coli causes $70-80 \%$ of them [10]. Most infections are endogenous in origin [10]. Asymptomatic bacteriuria can have serious consequences for the foetus and/or mother [10]. However, knowledge about the risk factors for carriage of resistant E. coli in the women of reproductive age group is lacking in general and especially from India. Screening the commensal $E$. coli in antenatal women for antibiotic resistance pattern will provide guidelines for empiric therapy especially for sick new-borns. Molecular analysis of these isolates will provide prevalence of antibiotic resistant genes present in $E$. coli in the community. The aim of the study is to ascertain the factors associated with the carriage of resistant commensal $E$. coli in pregnant women and further to characterize the genotypic determinants of antibiotic resistance in them.

\section{Methods}

\section{Study setting, study participants, enrolment and survey procedure}

The study was conducted in Obstetrics and Gynaecology outpatient clinics of a teaching and a non-teaching hospital in Ujjain, Madhya Pradesh, India during a 15month period from November 2007 to February 2009.
Both the hospitals cater predominantly to rural populations. Women between 18 to 49 years of age coming for routine antenatal check up were included in the study. Patients requiring emergency admission or with genital infections were not included.

Study participants were interviewed using a questionnaire containing details of patient particulars: age, family size, education, occupation of the main breadwinner, a reported history of antibiotic use in the previous four weeks and reported hospitalization in the previous four weeks. The questionnaire was piloted for one month to ascertain feasibility of data collection and to train the study assistants. Verbal informed consent was obtained from all participants after explaining the purpose of the study. The Ethics Committee of R.D. Gardi Medical College approved the study (approval number 41/2007).

\section{Sample collection, isolation and identification of $E$. coli}

Perianal swabbing was done using sterile, moistened cotton swabs. The collected samples were placed in Amies transport media with charcoal (HiMedia, Mumbai, India). Swabs were transported on ice to microbiology diagnostic laboratory within four hours of collection. Swabs were plated on MacConkey agar. All swabs grew E. coli.

E. coli were identified by standard recommonded methods [11]. Five colonies morphologically resembling of $E$. coli were selected and identified biochemically [11]. A single isolate from the pool of five colonies was selected for further characterization.

\section{Phenotypic determination of antibiotic susceptibility}

Antibiotic susceptibility testing was done using the KirbyBauer disc diffusion method. Disc strengths were as recommended by Clinical and Laboratory Standards Institute (CLSI) guidelines [12]. The plates were incubated at $35^{\circ} \mathrm{C}$ for 18 to 24 hours. Diameter and inhibition zones produced by the antibiotic disc were measured to the nearest millimetre. E. coli ATCC 25922 was used as the reference strain. Antibiotics tested were: ampicillin, cefuroxime, ceftriaxone, cefixime, ceftazidime, nalidixic acid, norfloxacin, ciprofloxacin, ofloxacin, gentamicin, amikacin, chloramphenicol, tetracycline, co-trimoxazole, nitrofurantoin, amoxicillin/clavulanate and piperacillin/tazobactum and imipenem. For calculations all isolates showing zone of inhibition indicating intermediate susceptibility were considered resistant. Multi-drug resistance (MDR) isolates were defined as those isolates having co-resistance to at least three different antibiotic classes [13]. Resistance of the MDR isolates was confirmed by Minimum Inhibitory Concentration (MIC) using agar dilution method for quinolones (ciprofloxacin, ofloxacin) and third generation cephalosporins (cefotaxim, ceftazidime) according to CLSI guidelines [12]. 
Extended Spectrum Beta-Latamase (ESBL) were detected phenotypically by the combined disc diffusion

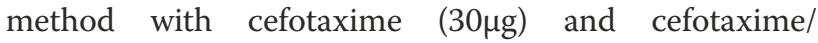
clavulanic acid (30/10 $\mu \mathrm{g})$ and ceftazidime $(30 \mu \mathrm{g})$ and ceftazidime/clavulanic acid (30/10 $\mu \mathrm{g})$ according to CLSI guidelines [12].

\section{Detection of genotypic determinants for ESBLs and resistance to quinolones}

Multiplex Polymerase Chain reactions (PCR) were used to detect genes coding for beta-lactamases. Total bacterial DNA from selected MDR E. coli showing ESBL production phenotypically was extracted by alkaline lysis method [14]. Amplification and identification of ESBL encoding genes $\left(b l a_{C T X-M}, b l a_{T E M}\right.$ and $\left.b l a_{S H V}\right)$ was done using previously described primers [15].

A separate multiplex PCR was done for detecting plasmid mediated quinolone resistance genes (PMQR; qnrA, $q n r B$, qnrS, aac(6')-Ib-cr and qepA) using previously described primers [16]. After PCR amplification, products were visualized under gel documentation system. Chromosomally mediated quinolone resistance was detected using PCR and DNA sequencing of gyr $A$ and par $C$ genes [17]. The purified PCR products were sequenced with $\mathrm{ABI}$ 3730XL (Applied Biosystems, USA) sequencer. The nucleic acid sequences were analyzed by Basic Local Alignment Search Tool available at the National Center for Biotechnology database. The nucleic acid sequences were submitted to Genbank (GenBank accession numbersKC795246 - KC 795255, KC795239 - KC795245, KC788561, КC788562).

\section{Rep-PCR typing of MDR E. coli isolates}

The molecular epidemiology of the MDR E. coli was done by Rep-PCR using BOX A1R (5'-CTACGGC AAGGCGACGCTGACG-3') primers as previously described [18]. PCR analysis was performed on a total of $25 \mathrm{ml}$ reaction mixture using $3 \mu \mathrm{l}$ of total bacterial DNA, as previously reported. PCR products were then separated by electrophoresis in 1.5\% agarose gels with $1 \mathrm{XTAE}$ running buffer at $8 \mathrm{~V} / \mathrm{cm}$ for 70 minutes and stained with Ethidium bromide $(0.5 \mu \mathrm{g} / \mathrm{ml})$, (Sigma Aldrich), for 30 minutes and visualized using a UV trans-illuminator. DNA molecular weight marker (O'GenerulerTM 100 bp DNA ladder; Fermentas) was used as a molecular size standard. Gel images were normalized, bands were identified and the data were statistically analysed by using Bionumerics software version 3.5 (Applied Maths, Kortrijk, Belgium). Clustering of patterns was performed by Unweighted Pair Group with Arithmetic averages (UPGMA) and dendrogram was created using the Dice Similarity Coefficient [18].

\section{Statistical analysis}

The data was entered in EpiData Entry (version 3.1) and then transferred to Stata 10.0 (Stata Corp. College Station, Texas, USA) software for statistical analysis. Frequency and percentages are presented for categorical data. Pearson Chi square test with 95\% confidence interval $(95 \% \mathrm{CI})$ was used to calculate odds ratios (OR) for potential risk factors associated with outcome variable carriage of MDR isolates of E. coli. Crude ORs were calculated from two by two tables. Multi-variable logistic regression models were used to calculate adjusted OR in the final model. The dichotomized explanatory variables included were, occupation of the breadwinner (self employed versus salaried), reported antibiotic use in the previous four weeks (yes versus no), reported hospitalization in the previous four weeks (yes versus no). Categorical variables included, age group in years (15 to 19,20 to 29,30 to 39 and 40 to 45 ), family size (less than or equal to 4, 5 to 10 and more than 10 members) and education (illiterate, up-to primary, up-to higher secondary and graduate or post-graduate). A $P$ value less than or equal to 0.05 was considered significant. The goodness of fit for the model was tested by examining the Receiver Operating Characteristics (ROC) curve plot [19]. The area under the ROC curve was 0.944 for the model for MDR E. coli meeting the criteria for excellent model determination [19].

\section{Results}

\section{Study population and enrolment}

A total of 730 women were approached of which 710 were enrolled. Of the 710 women enrolled, 412 (58\%) were from teaching hospital and remaining from the non-teaching hospital. The mean age of the women was 26 years (95\% confidence interval, CI 26 to 27, range 15 to 44 years) (Table 1 ).

\section{Detection of antibiotic-resistant phenotype and factors associated with carriage of MDR E. coli}

The antibiotic resistance pattern to selected antibiotics for $710 \mathrm{E}$. coli isolates from 710 antenatal women is shown in Table 2. A high number ( $\mathrm{n}=668,94 \%$; $95 \% \mathrm{CI}$ 92.4 to 95.8) of E. coli isolates showed resistance to at least one of the groups of antibiotics tested. All the isolates were susceptible to imipenem. Resistance was found to the commonly prescribed oral antibiotics, nalidixic acid (77\%), tetracycline (69\%), ampicillin (55\%), cotrimoxazole $(48 \%)$, cefixime (32\%), ciprofloxacin $(28 \%)$ and amoxicillin/clavulanate (27\%). The resistance to third generation cephalosporins was seen in the range of 17 to $19 \%$ and that to piperacillin/tazobactam and amikacin 3\% and $7 \%$ respectively.

Of the 127 isolates that were resistant to third generation cephalosporins, 109 isolates were seen to produce 
Table 1 Multiple logistic regression analysis of factors associated with carriage of multi-drug resistant $E$. coli among healthy women attending antenatal clinics in two hospitals in Ujjain, India

\begin{tabular}{|c|c|c|c|c|c|c|}
\hline \multirow[t]{2}{*}{ Factor } & \multirow{2}{*}{$\begin{array}{l}\text { Total } \\
\mathrm{n}=710\end{array}$} & \multirow[b]{2}{*}{$\%^{a}$} & \multicolumn{4}{|l|}{ MDR } \\
\hline & & & $\mathrm{n}=35$ & $\%^{a}$ & OR $(95 \% \mathrm{Cl})$ & $P$ value \\
\hline \multicolumn{7}{|l|}{ Age (in years) ${ }^{b}$} \\
\hline 15 to 19 & 55 & 95 & 2 & 5 & 1 & \\
\hline 20 to 29 & 434 & 94 & 20 & 6 & $0.59(0.13-2.67)$ & 0.49 \\
\hline 30 to 39 & 201 & 94 & 10 & 6 & $0.50(0.09-2.70)$ & 0.42 \\
\hline 40 to 45 & 20 & 80 & 3 & 20 & $2.19(0.23-20.9)$ & 0.49 \\
\hline \multicolumn{7}{|l|}{ Education $^{\text {b }}$} \\
\hline Illiterate & 393 & 94 & 17 & 6 & 1 & \\
\hline Up-to primary & 240 & 97 & 6 & 3 & $0.69(0.21-2.18)$ & 0.53 \\
\hline Up-to higher secondary & 47 & 91 & 3 & 9 & $1.27(0.26-6.27)$ & 0.76 \\
\hline Graduate or post graduate & 30 & 60 & 9 & 40 & $3.98(1.05-15.10)$ & 0.04 \\
\hline \multicolumn{7}{|l|}{ Occupation } \\
\hline Salaried & 207 & 87 & 19 & 13 & 1 & \\
\hline Self-employed & 503 & 96 & 16 & 4 & $0.41(0.15-1.06)$ & 0.06 \\
\hline \multicolumn{7}{|l|}{ Family size ${ }^{b}$} \\
\hline Less than or equal to 4 & 339 & 94 & 14 & 6 & 1 & \\
\hline Between 5-10 & 321 & 96 & 10 & 4 & $0.51(0.17-1.47)$ & 0.21 \\
\hline More than 10 & 50 & 70 & 11 & 30 & $4.97(1.51-16.33)$ & 0.008 \\
\hline \multicolumn{7}{|c|}{ Reported antibiotic usage (last 4 weeks) } \\
\hline No & 663 & 97 & 13 & 3 & 1 & \\
\hline Yes & 47 & 36 & 22 & 64 & $17.01(6.35-45.51)$ & $<0.001$ \\
\hline \multicolumn{7}{|c|}{ Reported Hospitalization (last 4 weeks) } \\
\hline Yes & 659 & 97 & 13 & 3 & 1 & \\
\hline No & 51 & 41 & 22 & 59 & $26.99(10.32-70.5)$ & $<0.001$ \\
\hline
\end{tabular}

$\%^{\mathrm{a}}$ row percentage; ${ }^{\mathrm{b}}$ The first value within the variable acted as reference value for logistic regression; OR- Odds ratio; Cl-confidence interval; OR significant at $P=0.05$ are shown in bold face; MDR- multi-drug resistance (co-resistance to three different classes of antibiotics).

ESBLs and of these 35 isolates were MDR. $\mathrm{MIC}_{50}$ and $\mathrm{MIC}_{90}$ for cefotaxime, ceftazidime, norfloxacin, ciprofloxacin and ofloxacin were calculated for these isolates (Table 3). The assay for MIC showed high levels of resistance to third generation cephalosporins and quinolones.

The statistically significant factors associated with carriage of MDR E. coli are shown in Table 1 and are as follows: "graduate or post-graduate education" Odds Ratio (OR) 3.98 (95\% CI 1.05 to $15.10 ; \quad \mathrm{P}=0.04)$; "self employed" OR 0.41 (95\% CI 0.15 to 1.06; P = 0.05); "family size more than 10 members" OR 4.97 (95\% CI 1.51 to 16.33; $\mathrm{P}=0.008$ ); reported "antibiotic usage in last four weeks" OR 17.01 ( 6.35 to 45.51; $\mathrm{P}<0.001$ ) and "history of hospitalization in the last four weeks" OR 26.99 (95\% CI 10.32 to $70.50 ; \mathrm{P}<0.001)$. The statistically significant factors associated with carriage of ESBL producing isolates are: "antibiotic usage in last four weeks" OR 5.21 (3.12 to 11.28 ; $\mathrm{P}<0.001$ ) and "history of hospitalization in the last four weeks" OR 7.82 (95\% CI 4.31 to 10.50 ; $\mathrm{P}<0.001)$.

\section{Detection of antibiotic resistance coding genes}

The multiplex PCR was done for detection of betalactamase producing genes. Of the 35 MDR isolates, plasmid mediated resistance to cephalosporins was due to bla $_{\mathrm{CTX}-\mathrm{M}-15}(26 / 35=74 \%), \quad$ bla $a_{\mathrm{TEM}}{ }_{-1}(26 / 35=74 \%)$ and $b l a_{\mathrm{OXA}-1}(17 / 35=49 \%)$. The $b l a_{\mathrm{CTX}-\mathrm{M}^{-1} 15}$ and $b l a_{\mathrm{TEM}-1}$ were seen in 19 (54\%), bla $a_{\mathrm{CTX}-\mathrm{M}-15}$ and bla $a_{\mathrm{OXA}-1}$ in 15 (43\%), bla $a_{\mathrm{TEM}-1}$ and $b l a_{\mathrm{OXA}-1}$ in $12(34 \%)$ and $b l a_{C T X-M-15}$, $b l a_{\mathrm{TEM}-1}$ and $b l a_{\mathrm{OXA}-1}$ in 12 (34\%). All cefotaxime and ceftazidime resistant isolates were also screened for the presence of the $b l a_{\mathrm{SHV}}$ gene and none was found to carry it. We sequenced TEM gene and all were found to be TEM-1. The screening for PMQR genes showed one isolate positive for qnrA, one for qnrS1 gene and 23 isolates were positive for $a a c\left(6^{\prime}\right)-I b-c r$. It was note worthy that all the isolates carrying PMQR genes also carried the $b l a_{\mathrm{TEM}-1}$ 
Table 2 Co-resistance pattern of ten antibiotics for $710 \mathrm{E}$. coli isolates from healthy women attending antenatal clinics in two hospitals, Ujjain, India

\begin{tabular}{|c|c|c|c|c|c|c|c|c|c|c|}
\hline & n (\%) & $\begin{array}{c}\text { Amoxycillin/ } \\
\text { Clavn (\%) }\end{array}$ & $\begin{array}{c}\text { Pipracillin/ } \\
\text { Tazobactumn (\%) }\end{array}$ & $\begin{array}{c}\text { Ceftriaxonen } \\
(\%)\end{array}$ & $\begin{array}{l}\text { Cefiximen } \\
(\%)\end{array}$ & $\begin{array}{c}\text { Ciprofloxacinn } \\
\text { (\%) }\end{array}$ & $\begin{array}{l}\text { Amikacinn } \\
(\%)\end{array}$ & $\begin{array}{c}\text { Tetracyclinen } \\
(\%)\end{array}$ & $\begin{array}{c}\text { Co-trimoxazolen } \\
(\%)\end{array}$ & $\begin{array}{c}\text { Chloramphenicoln } \\
(\%)\end{array}$ \\
\hline \multirow[t]{2}{*}{ Ampicillinn (\%) } & \multirow{2}{*}{$\begin{array}{l}388 \\
(55)\end{array}$} & 183 & 19 & 127 & 172 & 170 & 32 & 317 & 251 & 34 \\
\hline & & (26) & (3) & (18) & (24) & (24) & (5) & (45) & (35) & (5) \\
\hline \multirow[t]{2}{*}{ Amoxycillin/clav n (\%) } & \multirow{2}{*}{$\begin{array}{l}189 \\
(27)\end{array}$} & - & 15 & 114 & 139 & 127 & 21 & 173 & 163 & 27 \\
\hline & & & (2) & (16) & (20) & (18) & (3) & (24) & (23) & (4) \\
\hline \multirow{2}{*}{$\begin{array}{l}\text { Pipracillin/ } \\
\text { tazobactumn (\%) }\end{array}$} & 23 & & - & 12 & 19 & 15 & 7 & 23 & 18 & 21 \\
\hline & (3) & & & (2) & (3) & (2) & (1) & (3) & (3) & (3) \\
\hline \multirow[t]{2}{*}{ Ceftriaxonn (\%) } & 133 & & & - & 129 & 107 & 18 & 124 & 116 & 24 \\
\hline & (19) & & & & (18) & (15) & (3) & (17) & (16) & (3) \\
\hline \multirow[t]{2}{*}{ Cefiximen (\%) } & 226 & & & & - & 130 & 23 & 117 & 172 & 33 \\
\hline & (32) & & & & & & (3) & (16) & (24) & (5) \\
\hline \multirow[t]{2}{*}{ Ciprofloxacinn (\%) } & 198 & & & & & - & 25 & 182 & 160 & 26 \\
\hline & (28) & & & & & & (4) & (26) & (23) & (4) \\
\hline \multirow[t]{2}{*}{ Amikacinn (\%) } & 47 & & & & & & - & 44 & 25 & 20 \\
\hline & (7) & & & & & & & (6) & (3) & (3) \\
\hline \multirow[t]{2}{*}{ Tetracyclinen (\%) } & 491 & & & & & & & - & 278 & 39 \\
\hline & $(69)$ & & & & & & & & (39) & (5) \\
\hline \multirow[t]{2}{*}{ Co-trimoxazolen (\%) } & 340 & & & & & & & & - & 31 \\
\hline & $(48)$ & & & & & & & & & (4) \\
\hline \multirow{2}{*}{$\begin{array}{l}\text { Chloramphenicoln } \\
(\%)\end{array}$} & 40 & & & & & & & & & - \\
\hline & (6) & & & & & & & & & \\
\hline
\end{tabular}


Table 3 MICs of 35 MDR commensal E. coli isolates

\begin{tabular}{lccc}
\hline Antibiotic & Range $(\boldsymbol{\mu g} / \mathbf{m L})$ & MIC $\mathbf{5 0}(\boldsymbol{\mu g} / \mathbf{m L})$ & MIC90 $(\boldsymbol{\mu g} / \mathbf{m L})$ \\
\hline Ciprofloxacin & $0.125-512$ & 128 & 256 \\
Norfloxacin & $0.125-512$ & 512 & $>512$ \\
Ofloxacin & $0.125-512$ & 64 & 128 \\
Cefotaxime & $0.125-512$ & $>512$ & $>512$ \\
Ceftazidime & $0.125-512$ & 32 & 128 \\
\hline
\end{tabular}

and $b l a_{\mathrm{CTX}-\mathrm{M}-15}$ gene. There were 17 isolates having both bla $a_{\text {CTX-M-15 }}$ and $a a c\left(6^{\prime}\right)-I b-c r$ genes (Figure 1). PCR and DNA sequencing for mutations in gyr $A$ and par $C$ genes indicated chromosomally mediated quinolone resistance. Sequence analysis of these genes indicated that all the 35 isolates had amino acid substitutions at QRDR regions at gyr $A(\mathrm{D} 87 \mathrm{~N} / \mathrm{S} 83 \mathrm{~L})$ and par C (S 80l) genes.

Chromosomally mediated resistance to quinolones was seen in all the 35 isolates based on the presence of gyrA and parC genes. Plasmid mediated resistance to cephalosporins and quinolones was seen in 22/35 (63\%). Of these 21 isolates carried the $\operatorname{aac}\left(6^{\prime}\right)-\mathrm{Ib}-\mathrm{cr}$ genes and only one isolate carried the qnrS along with bla $a_{\mathrm{CTX}-\mathrm{M}-15}$, $b l a_{\mathrm{TEM}-1}$ and $b l a_{\mathrm{OXA}-1}$ The other $q n r A$ and $q n r S$ genes carrying plasmid were seen along with the plasmid coding for cephalosporin resistance. Details of MDR isolates along with MIC values are included in the supplementary data (Additional file 1: Table S1). The dendrogram (Figure 1) depicts the genetic similarity of MDR E .coli. The genes coding for plasmid mediated and chromosomally mediated resistance to cephalosporins and quinolones are also depicted at Figure 1.

\section{Discussion}

In the present study it was found that out of the $710 \mathrm{E}$. coli isolated from women attending antenatal clinics in Ujjain, India $94 \%$ were resistant to at least one of the antibiotic groups tested. The statistically significant factors associated with carriage of MDR E. coli were better education, overcrowding (family size more than 10

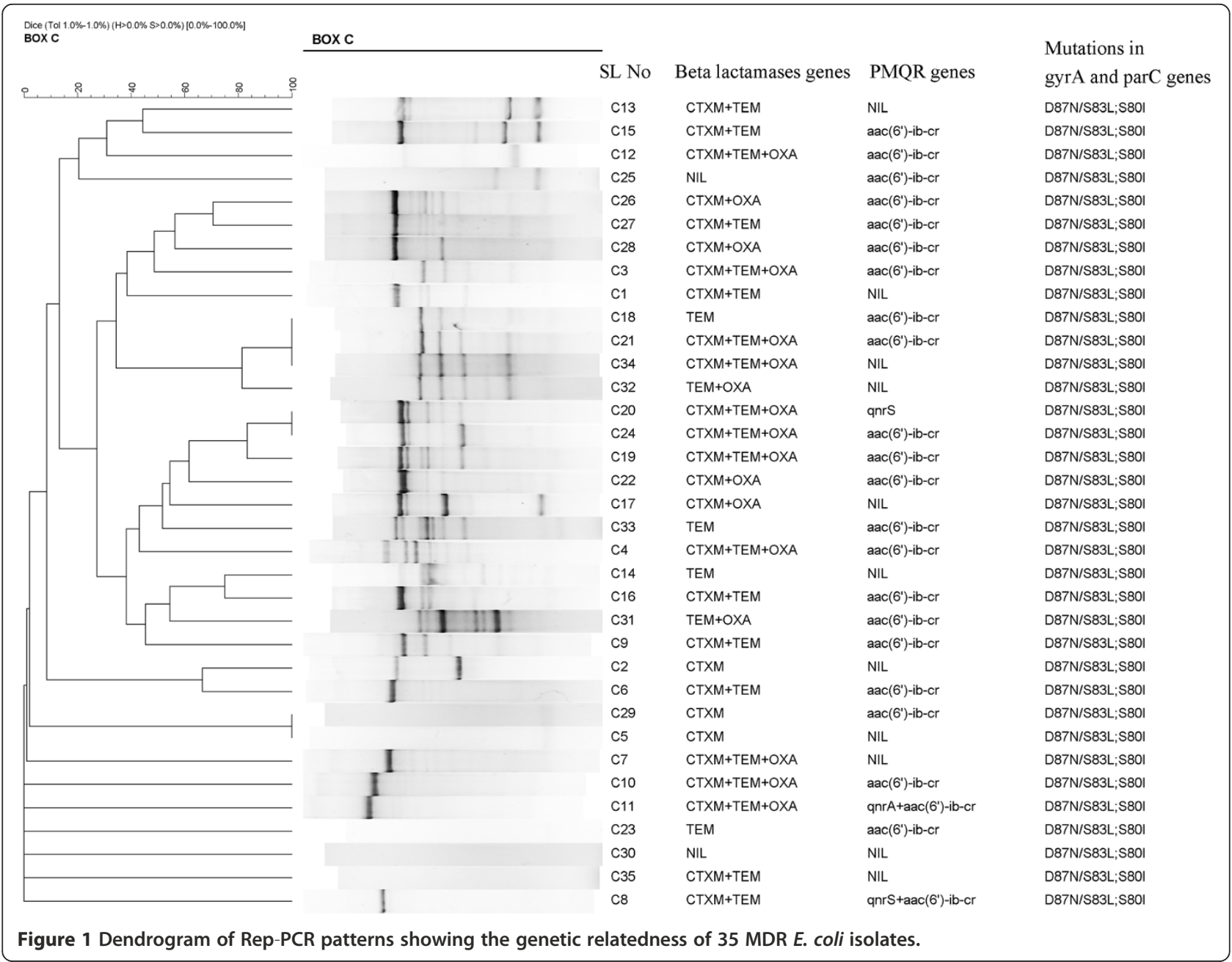


members) history of antibiotic use and/or hospitalization in the last four weeks.

Quinolone resistance is usually chromosomally mediated [20]. All 35 multi-resistant isolates showed presence of gyrA and $\operatorname{parC}$ genes, which are chromosomally mediated. The $a a c\left(6^{\prime}\right)-I b-c r$ gene accounted for $95 \%$ of the $\mathrm{PMQR}$ genes. Similar findings in pathogenic E. coli have been reported elsewhere in India [21] and in E. coli isolated from hospital wastewater in our setting [22]. Plasmid mediated resistance to cephalosporins was largely due to bla СтX-M -15 which is in keeping with other studies done in India $[21,23]$. The $b a_{\text {TEM-1 }}$ is not been subtyped therefore no comment can be made for its corelation with ESBL production. It is interesting to note that $b l a_{\text {SHV }}$ was not detected. The presence of genes coding for extended spectrum of beta lactamases and plasmid mediated quinolone resistance in commensal E. coli is disconcerting.

Studies from India $[7,24]$ and other low-middle income countries [25] have reported lower rates of resistance (range of 32 to $63 \%$ ) to a single antibiotic compared to the present study (94\%). The difference in the resistance rates could be due to variation in the geographical area of the study $[7,8,26]$ and also is dependent on the pattern of antibiotic prescribing in the local community $[27,28]$. The ESBL rate $(15 \%)$ in the present study is lower than that reported among pathogenic E. coli (69\%) isolated from patients with clinical infections in the same geographical area [29].

The majorities of women enrolled in the study were either illiterate or had only a primary education (Table 1). Women with higher education had a higher likelihood of carriage of MDR E. coli. This could be a chance association and needs further validation. But, women with higher education may also be socio-economically better off and thus more likely to seek health-care and consequently have a greater exposure to antibiotics [30]. Most self-employed women enrolled in the study were daily wage workers, and consequently, probably, had limited opportunity to seek medical care, limiting their antibiotic exposure.

Exposure to hospital environment especially hospitalization in intensive care units is a major risk factor for carriage of multi-drug resistant bacteria especially in resource poor settings where hospitals can have high infection rates and spread of multi-drug resistant pathogens [25,31]. A multitude of factors including poor infrastructure of hospitals, low compliance with hand-hygiene, heavy workload with understaffing, overcrowding, lack of or poorly functioning infection control programme contribute to the problem [31].

In the present study a significantly higher MDR carriage among women living in larger families (more than 10 members), OR 4.97 (95\% CI 1.51 to $16.33 ; \mathrm{P}=0.008$ ) was found. Similar results have been reported in postmenopausal women in our setting [32]. Over-crowding combined with inadequate hygiene and sanitary facilities and sewage disposal, would lead to greater sharing of commensal flora in families and communities $[8,32]$. In a study among primary school children in rural Tamil Nadu over crowding in classrooms was associated with increased carriage of antibiotic resistant commensal E. coli [24]. Thus, the dynamics of bacterial transmission due to over crowding is worthy of further investigation.

The rate and amount of antibiotic use in community an important determinant of increasing antibiotic resistance in bacteria $[27,28]$. A meta analysis and review on the effect of antibiotic prescribing in a primary-care setting on antimicrobial resistance in individual patients included five studies of urinary tract infections (14348 participants), the pooled odds ratio (OR) for resistance was 2.5 (95\% CI 2.1 to 2.9 ) within two months of antibiotic treatment [33]. The OR at one month (only one study) was 6.1 (95\% CI 2.8 to 13.4) [33]. Recent antibiotic use was associated with increased risk of carriage of resistant E. coli, OR 1.8 (95\% CI 1.5 to 2.3 ) in a study from Indonesia [25].

The ESBL production is the commonest mechanism of resistance to cephalosporins in Enterobacteriaceae [2]. Phenotypic detection of ESBL production was in 15\% isolates in the present study, which is much lower than the $51 \%$ reported in a study from China [34].

The $b l a_{\mathrm{CTX}-\mathrm{M}-15}$ and $b l a_{\mathrm{TEM}-1}$ coded genes are widespread in E. coli [2]. The detection of bla CTX-M-15 and bla $a_{\text {TEM-1 }}$ genes as shown in Figure 1 is similar to that in Latin America [9]. In the present study it has been noted that a majority of MDR E coli isolates (48\%) were carrying $a a c\left(6^{\prime}\right)-I b-c r$ gene. These isolates also showed high MIC to ciprofloxacin and ofloxacin probably due to chromosomally mediated resistance (par $A$ and par $C$ ) (Table 3). Co-residence of bla CTX-M-15, qnr and aac(6')$\mathrm{Ib}$ - $\mathrm{cr}$ genes on the same plasmid has been reported elsewhere [35].

PMQR genes code for low levels of quinolone resistance [36]. The presence of PMQR gene in MDR isolates was $4 \%$, which is similar to that in a study from Republic of Korea [16]. It is interesting to notice that chromosomal mediated quinolone resistance coded by mutation in QRDR regions of gyr $A$ and par $C$ genes was present in all MDR $E$ coli isolates in the present study. A study in Ghana on quinolone-resistant $E$. coli in the faecal flora also reported the presence of $q n r$ genes and amnio acid substitutions at gyrA and par $C$ genes [37].

An analysis of resistance pattern of commensal E. coli can be helpful in deciding empiric treatment of choice for suspected neonatal infections. Neonatal sepsis with multi-drug resistant gram negative organisms resistant to ampicillin, third generation cephalosporins and 
gentamicin caused high mortality (26\%) in neonates in a neonatal intensive care unit (NICU) in India [38]. The current choices of therapy in our NICU are in line with the most sensitive patterns described ie third generation cephalosporins along with an aminoglycoside (Table 2). However, the last resort antibiotics (eg. vancomycin and imipenem) are now increasingly being used in view of increasing resistance [29] in our NICU to salvage septic neonates.

The most important strength of this study is the combination of epidemiological and molecular methods for the identification of factors associated with carriage of resistant bacteria. Antenatal women are a population, which is at a low risk for receiving antibiotics. Despite this a history of antibiotic therapy was identified as an important risk factor associated with carriage of resistant bacteria. The fact underscores the importance of prudent antibiotic use. A structured questionnaire was used which could have resulted in us missing other factors related to carriage of resistant $E$. coli like environmental factors and food chain related factors.

\section{Conclusions}

The presence of antibiotic resistance mediating genes in commensal bacteria provides information on the occurrence of multi-drug resistance bacteria in a given geographical area. The presence of genes coding for extended spectrum of beta lactamases and plasmid mediated quinolone resistance in commensal E. coli is disconcerting.

This is compounded in resource poor settings with overcrowding and poor sanitation, which seem to aid the spread of multi-drug resistant bacteria within a community. This provides strong basis of good antibiotic stewardship.

\section{Additional file}

Additional file 1: Details of resistance mechanisms of the 35 multidrug resistant $E$. coli among healthy women attending antenatal clinics in two hospitals in Ujjain, India.

\section{Competing interests}

The authors declared that they have no competing interests.

\section{Authors' contributions}

AP, SC, KM, RM and CSL participated in the conception and design of the study. KM and AP collected data in the field. SC and RM carried out the molecular genetic studies, participated in the sequence alignment. AP and SC performed the statistical analysis and drafted the manuscript. CSL coordinated the study. AP, SC, KM, RM and CSL revised the paper critically for substantial intellectual content. All authors read and approved the final manuscript.

\section{Acknowledgements}

We thank all the participating physicians and patients for their co-operation during data collection and Dr VK Mahadik, Medical Director, RD Gardi Medical College, for administrative support during the project. This project is funded by the VR (the Swedish Research Council) and the Asia link. We thank the Erasmus Mundus External Cooperation Window lot 15 and The Swedish Research School for Global Health for scholarships to AP for his doctoral studies at Division of Global Health (IHCAR), Karoliska Institutet, Sweden. We also thank Sathish Mundayoor and Biljo V. Joseph at RGCB, Thiruvananthapuram, Kerala for providing support for BioNumerics software analysis.

\section{Author details}

${ }^{1}$ Global Health (IHCAR), Department of Public Health Sciences Karolinska Institutet, Tomtebodavägen 18 A 9, Stockholm 17177, Sweden. ${ }^{2}$ Department of Pediatrics, R.D. Gardi Medical College, Surasa, Ujjain 456010, India. ${ }^{3}$ Department of Women and Children's Health, International Maternal and Child Health Unit, Uppsala University, Uppsala, Sweden. ${ }^{4}$ Department of Microbiology, St Johns Research Institute, Bangalore, India. ${ }^{5}$ Department of Obstetrics and Gynaecology, R.D. Gardi Medical College, Ujjain 456010, India.

Received: 2 February 2013 Accepted: 22 April 2013

Published: 2 May 2013

\section{References}

1. Schultsz C, Geerlings S: Plasmid-mediated resistance in enterobacteriaceae: changing landscape and implications for therapy. Drugs 2012, 72(1):1-16.

2. Bailey JK, Pinyon JL, Anantham S, Hall RM: Commensal Escherichia coli of healthy humans: a reservoir for antibiotic-resistance determinants. J Med Microbiol 2011, 59(Pt 11):1331-1339.

3. Boucher HW, Talbot GH, Bradley JS, Edwards JE, Gilbert D, Rice LB, Scheld M, Spellberg B, Bartlett J: Bad bugs, no drugs: no ESKAPE! an update from the infectious diseases society of america. Clin Infect Dis 2009, 48(1):1-12.

4. Ron EZ: Distribution and evolution of virulence factors in septicemic Escherichia coli. Int J Med Microbiol 2010, 300(6):367-370.

5. Kumarasamy KK, Toleman MA, Walsh TR, Bagaria J, Butt F, Balakrishnan R, Chaudhary U, Doumith M, Giske CG, Irfan S, et al: Emergence of a new antibiotic resistance mechanism in india, pakistan, and the UK: a molecular, biological, and epidemiological study. Lancet Infect Dis 2010, 10(9):597-602.

6. Ewers C, Bethe A, Semmler T, Guenther S, Wieler LH: Extended-spectrum beta-lactamase-producing and AmpC-producing Escherichia coli from livestock and companion animals, and their putative impact on public health: a global perspective. Clin Microbiol Infect 2012, 18(7):646-655.

7. Mathai E, Chandy S, Thomas K, Antoniswamy B, Joseph I, Mathai M, Sorensen $T L$, Holloway $K$ : Antimicrobial resistance surveillance among commensal Escherichia coli in rural and urban areas in southern india. Trop Med Int Health 2008, 13(1):41-45.

8. Nys S, Okeke IN, Kariuki S, Dinant GJ, Driessen C, Stobberingh EE: Antibiotic resistance of faecal Escherichia coli from healthy volunteers from eight developing countries. J Antimicrob Chemother 2004, 54(5):952-955.

9. Pallecchi L, Bartoloni A, Fiorelli C, Mantella A, Di Maggio T, Gamboa H, Gotuzzo E, Kronvall G, Paradisi F, Rossolini GM: Rapid dissemination and diversity of CTX-M extended-spectrum beta-lactamase genes in commensal Escherichia coli isolates from healthy children from lowresource settings in latin america. Antimicrob Agents Chemother 2007, 51(8):2720-2725

10. Schnarr J, Smaill F: Asymptomatic bacteriuria and symptomatic urinary tract infections in pregnancy. Eur J Clin Invest 2008, 38(Suppl 2):50-57.

11. Murray PRBE, Pfaller MA, Tenover FC, Yolken RH: Manual of clinical microbiology. 7th edition. Washington DC: ASM press; 1999.

12. Clinical and Laboratory Standards Institute: M100-S20-U. Performance standards for antimicrobial susceptibility testing: 20th informational supplement. Wayne, PA: CLSI; 2010.

13. Magiorakos AP, Srinivasan A, Carey RB, Carmeli Y, Falagas ME, Giske CG, Harbarth S, Hindler JF, Kahlmeter G, Olsson-Liljequist B, et al: Multidrugresistant, extensively drug-resistant and pandrug-resistant bacteria: an international expert proposal for interim standard definitions for acquired resistance. Clin Microbiol Infect 2012, 18(3):268-281.

14. Sambrook JFE, Maniatis T: Molecular cloning: a laboratory manual. NY, USA: Cold Spring Harbor Laboratory Press; 1989.

15. Dallenne C, Da Costa A, Decre D, Favier C, Arlet G: Development of a set of multiplex PCR assays for the detection of genes encoding important 
beta-lactamases in enterobacteriaceae. J Antimicrob Chemother 2010, 65(3):490-495

16. Kim HB, Park CH, Kim CJ, Kim EC, Jacoby GA, Hooper DC: Prevalence of plasmid-mediated quinolone resistance determinants over a 9-year period. Antimicrob Agents Chemother 2009, 53(2):639-645

17. Everett MJ, Jin YF, Ricci V, Piddock LJ: Contributions of individual mechanisms to fluoroquinolone resistance in 36 Escherichia coli strains isolated from humans and animals. Antimicrob Agents Chemother 1996, 40(10):2380-2386.

18. Goldberg TL, Gillespie TR, Singer RS: Optimization of analytical parameters for inferring relationships among Escherichia coli isolates from repetitiveelement PCR by maximizing correspondence with multilocus sequence typing data. Appl Environ Microbiol 2006, 72(9):6049-6052.

19. Lemeshow S, Hosmer DW Jr: A review of goodness of fit statistics for use in the development of logistic regression models. Am J Epidemiol 1982, 115(1):92-106.

20. Li XZ: Quinolone resistance in bacteria: emphasis on plasmid-mediated mechanisms. Int J Antimicrob Agents 2005, 25(6):453-463.

21. Shahid M, Singh A, Sobia F, Rashid M, Malik A, Shukla I, Khan HM: bla(CTX$\mathrm{M}), \mathrm{bla}(\mathrm{TEM})$, and bla(SHV) in enterobacteriaceae from north-indian tertiary hospital: high occurrence of combination genes. Asian Pac J Trop Med 2011, 4(2):101-105.

22. Diwan V, Chandran SP, Tamhankar AJ, Stalsby Lundborg C, Macaden R: Identification of extended-spectrum beta-lactamase and quinolone resistance genes in Escherichia coli isolated from hospital wastewater from central india. J Antimicrob Chemother 2012, 67(4):857-859.

23. Pazhani GP, Chakraborty S, Fujihara K, Yamasaki S, Ghosh A, Nair GB, Ramamurthy T: QRDR mutations, efflux system \& antimicrobial resistance genes in enterotoxigenic Escherichia coli isolated from an outbreak of diarrhoea in ahmedabad, india. Indian J Med Res 2011, 134:214-223.

24. Seidman JC, Anitha KP, Kanungo R, Bourgeois AL, Coles CL: Risk factors for antibiotic-resistant E. Coli in children in a rural area. Epidemiol Infect 2009, 137(6):879-888.

25. Duerink DO, Lestari ES, Hadi U, Nagelkerke NJ, Severin JA, Verbrugh HA, Keuter M, Gyssens IC, van den Broek PJ: Determinants of carriage of resistant Escherichia coli in the indonesian population inside and outside hospitals. J Antimicrob Chemother 2007, 60(2):377-384.

26. Sahoo KC, Tamhankar AJ, Sahoo S, Sahu PS, Klintz SR, Lundborg CS: Geographical variation in antibiotic-resistant Escherichia coli isolates from stool, cow-dung and drinking water. Int J Environ Res Public Health 2012, 9(3):746-759.

27. Pathak A, Mahadik K, Dhaneria SP, Sharma A, Eriksson B, Lundborg CS: Surveillance of antibiotic consumption using the "focus of infection" approach in 2 hospitals in ujjain india. PLoS One 2012, 7(6):e38641.

28. Goossens $H$, Ferech M, Vander Stichele R, Elseviers M: Outpatient antibiotic use in europe and association with resistance: a cross-national database study. Lancet 2005, 365(9459):579-587.

29. Pathak A, Marothi Y, Kekre V, Mahadik K, Macaden R, Lundborg CS: High prevalence of extended-spectrum beta-lactamase-producing pathogens: results of a surveillance study in two hospitals in ujjain, india. Infect Drug Resist 2012, 5:65-73.

30. Mishra SK, Mukhopadhyay S: Socioeconomic correlates of reproductive morbidity among adolescent girls in sikkim india. Asia Pac J Public Health 2012, 24(1):136-150.

31. Alp E, Leblebicioglu H, Doganay M, Voss A: Infection control practice in countries with limited resources. Ann Clin Microbiol Antimicrob 2011, 10:36.

32. Pathak A, Mahadik K, Sharma R, Marothi Y, Sharma M, Macaden R, Lundborg CS: Factors associated with carriage of multi-resistant commensal Escherichia coli among postmenopausal women in Ujjain, India. Scand J Infect Dis 2012, 44(12):973-977.

33. Costelloe C, Metcalfe C, Lovering A, Mant D, Hay AD: Effect of antibiotic prescribing in primary care on antimicrobial resistance in individual patients: systematic review and meta-analysis. BMJ 2010, 340:c2096.

34. Li B, Sun JY, Liu QZ, Han LZ, Huang XH, Ni YX: High prevalence of CTX-M beta-lactamases in faecal Escherichia coli strains from healthy humans in fuzhou china. Scand J Infect Dis 2011, 43(3):170-174.

35. Jiang Y, Zhou Z, Qian Y, Wei Z, Yu Y, Hu S, Li L: Plasmid-mediated quinolone resistance determinants qnr and aac $\left(6^{\prime}\right)-\mathrm{lb}-\mathrm{cr}$ in extendedspectrum beta-lactamase-producing Escherichia coli and klebsiella pneumoniae in china. J Antimicrob Chemother 2008, 61(5):1003-1006.
36. El Salabi A, Walsh TR, Chouchani C: Extended spectrum beta-lactamases, carbapenemases and mobile genetic elements responsible for antibiotics resistance in gram-negative bacteria. Crit Rev Microbiol 2013, 39(2):113-122.

37. Namboodiri SS, Opintan JA, Lijek RS, Newman MJ, Okeke IN: Quinolone resistance in Escherichia coli from accra ghana. BMC Microbiol 2011, 11:44.

38. Viswanathan R, Singh AK, Basu S, Chatterjee S, Sardar S, Isaacs D: Multi-drug resistant gram negative bacilli causing early neonatal sepsis in india. Arch Dis Child Fetal Neonatal Ed 2012, 97(3):F182-187.

doi:10.1186/1471-2334-13-199

Cite this article as: Pathak et al:: Frequency and factors associated with carriage of multi-drug resistant commensal Escherichia coli among women attending antenatal clinics in Central India. BMC Infectious Diseases 2013 13:199.

\section{Submit your next manuscript to BioMed Central and take full advantage of:}

- Convenient online submission

- Thorough peer review

- No space constraints or color figure charges

- Immediate publication on acceptance

- Inclusion in PubMed, CAS, Scopus and Google Scholar

- Research which is freely available for redistribution

Submit your manuscript at www.biomedcentral.com/submit
C Biomed Central 